\title{
EDITORIAL
}

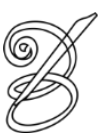

\section{LA INVESTIGACIÓN EN TRADUCCIÓN EN LAS UNIVERSIDADES ARGENTINAS}

a Argentina tiene una tradición fuertemente ligada a la traducción, actividad que supo ser
una de las puertas de entrada a nuevas corrientes literarias, a estéticas innovadoras y a
moldes de escritura experimentales. La Traductología por su lado, en tanto disciplina reciente, goza de un estatuto interdisciplinar que le permite establecer diálogos permanentes con campos tan diversos como la literatura, el psicoanálisis, la lingüística, el derecho, la sociología, la historia o la filosofía. En Argentina, como en tantos otros países, la Traductología va ganando su autonomía apartándose de la Lingüística, históricamente su disciplina «madre », para hacer su propio camino en la investigación universitaria, tema que nos convoca en el presente número de Belas Infiéis. Las universidades argentinas acompañan el desarrollo de la disciplina traductológica y concentran sus esfuerzos no solo en la formación de traductores profesionales sino también en el avance de la investigación. En los últimos años, la implementación de centros universitarios de investigación en Traductología, así como de estudios de posgrado, son prueba de ello. En este número fueron seleccionados trabajos que resultan representativos de la vitalidad y actualidad de la investigación traductológica en la Argentina, tanto en su vertiente aplicada a la didáctica como en su carácter interdisciplinario, en diálogo con la literatura, las políticas editoriales, el análisis del discurso, la crítica y la historia, por nombrar solo algunas disciplinas que enriquecen el enfoque traductológico.

Este volumen 8, número 2 de 2019 de la revista Belas Infiéis se abre con el artículo titulado "La utilidad del enfoque por tareas y de la noción de género discursivo en la didáctica de la traducción jurídica”, propuesto por las traductoras Julieta Amorebieta y Vera, Guillermina Remiro y Beatriz Munch, de la Facultad de Humanidades y Ciencias de la Educación de la Universidad 
Nacional de La Plata, Argentina. Integrantes del Proyecto de Investigación: "Estudios de Derecho Comparado: ¿Herramienta o método para la traducción jurídica y la didáctica de la traducción en Argentina?", las autoras presentan la metodología y las reflexiones sobre cómo abordar la traducción especializada en la asignatura “Traducción Jurídica y Económica en inglés 1”, tanto en el uso del lenguaje de especialidad como en la práctica de técnicas de investigación y de redacción de textos especializados. Su aproximación didáctica se muestra enriquecida por las nociones de "enfoque por tareas" y de género discursivo. Apuntalado por un marco teórico actual y sólido, el trabajo se propone dar respuestas concretas frente a la necesidad y el desafío de formar traductores profesionales con material producido localmente y adecuado particularmente al contexto argentino.

En "Simone de Beauvoir en Argentina: el rol de las editoriales y de las traducciones en la recepción de su obra", las traductoras Beatriz Cagnolati y Jovanka Vukovic, junto con la investigadora en género Dra. Luisa Femenías, abordan, desde la traductología, el feminismo filosófico y la teoría de género, la importante obra de Simone de Beauvoir, ampliamente difundida en el contexto argentino y latinoamericano a partir de los años 50. Las autoras se proponen hacer un correlato entre la actividad de traducción editorial y la recepción de la obra de la filósofa francesa, reseñando el paso de las traducciones por revistas tan importantes como Sur, dirigida por la escritora Victoria Ocampo, hasta sellos editoriales de prestigio en toda Latinoamérica. Complementa este estudio la resignificación, desde la teoría de género, de la terminología y sintaxis presentes en especial en la obra El segundo sexo (Le deuxième sexe). El artículo se cierra con una lista de traducciones de la obra beauvoiriana realizadas en Argentina, lo cual representa una gran trabajo de recopilación así como una ayuda para todo aquel interesado en la traducción de esta obra.

María Eugenia Ghirimoldi aborda en su artículo "Retos de la traducción del imaginario creole: negociar la distancia enunciativa entre texto original heterolingüe y traducción" el análisis de la traducción de la novela Texaco, del escritor martiniqueño Patrick Chamoiseau. Varios frentes de análisis guían este trabajo, como la reivindicación del ser creole, la construcción de un campo literario, la escritura híbrida en el cruce de lenguas y culturas y el texto literario heterolingüe. Sobre la base de la gestión de la alteridad en la traducción, la investigadora se detiene a observar el ethos del traductor y la negociación de la distancia enunciativa en la traducción de Texaco al español. Enriquecido con numerosos casos de estudio a lo largo de toda la obra analizada, el trabajo de Ghirimoldi constituye un interesante aporte tanto a los estudios traductológicos centrados en la 
problemática del texto heterolingüe como al análisis y reflexión de las relaciones entre traducción y cultura, en particular de la literatura y cultura caribeñas.

Por su parte, el trabajo "Sobre autotraducción y paratexto en Boquitas pintadas. Folletín de Manuel Puig" de la Dra. Giselle Rodas propone una mirada del escritor argentino Manuel Puig como traductor de su propia obra. La autora nos invita a sobrevolar la novela Boquitas pintadas desde la mirada de la autotraducción y su presencia en el paratexto literario. Investigadora en la Universidad de Lomas de Zamora y en la Universidad del Cine, Argentina, Rodas se detiene en las ediciones de la novela hacia el francés, el italiano y el inglés y analiza títulos, subtítulos, epígrafes e intertextos, en su objetivo de evidenciar mecanismos que se ajustan al horizonte de cada cultura receptora. Los casos de estudio la llevan a reflexionar sobre el estatuto de Puig como autotraductor y mediador cultural del paratexto en su novela.

Otro aporte valioso para este número lo ofrece Paula Salerno en su trabajo intitulado “Traducir y recrear. Estrategias de Aurora Venturini en Cantos de Maldoror: Satánica Trinidad". La autora parte de una caracterización de la escritora platense Aurora Venturini para luego abordar la traducción de Cantos de Maldoror... desde la traducción hermenéutica. Este enfoque le permite a Salerno rastrear las huellas de la traducción-recreación que realiza Venturini y concluir, entre otras interesantes reflexiones, que esta escritora consigue colocarse en un espacio de visibilidad literaria y logra ubicar su proyecto traductivo en un molde alejado del ideal de transparencia. La estética del mal propia de Lautréamont encuentra en Venturini un proyecto escriturario que estalla en diversas subjetividades y en el cual la voz de la escritora-traductora se erige como una instancia más de enunciación.

En "Una presencia de antología. La traducción al español de la poesía de Kathleen Raine”, María Laura Spoturno propone una lectura detallada, minuciosa y sólidamente documentada de la traducción hacia el español de la obra poética de la escritora británica Kathleen Raine. Objeto de una antología en la versión española, la obra de Raine aparece por ello necesariamente incompleta, situación de la cual parte Spoturno para detenerse a analizar los mecanismos que contribuyen a la recreación en español del poema "The Presence" escogido para su estudio. La autora va más allá en la indagación y propone sumar el caso de la versión al francés, decisión interesante para el análisis por cuanto en ese contexto de enunciación el poema se despliega en su integridad sin la intervención del antólogo. El análisis va acompañado de reflexiones y abundante bibliografía sobre la voz poética de Raine, el lenguaje poético y su tan peculiar problemática a la hora de ser traducido. 
La traducción al español de otra obra literaria es lo que también interesa a la profesora y traductora María Julia Zaparart, actual doctoranda del Área de Investigación en Traductología de la Universidad Nacional de La Plata. En su trabajo sobre "Patrick Modiano en español: el caso de Dora Bruder", Zaparart propone un análisis crítico de la versión en español de la novela Dora Bruder, caracterizada por una mezcla de elementos ficcionales y reales en los que el pasado y el presente se confunden y conviven en un espacio de tensión. Así, la constante referencia a la topografía parisina remite a una posmemoria que es constitutiva de la ambigüedad de la narración, pero que también contribuye a la lectura en clave realista de la novela. La autora analiza, mediante ejemplos concretos extraídos de las páginas de Dora Bruder, así como con datos precisos de las diferentes ediciones, si la misma sistematicidad del original se mantiene en la versión en español, llegando a conclusiones agudas que contribuyen al campo de la crítica de traducciones.

El último trabajo de este número lo constituye una traducción del artículo del profesor Ori Preuss, de la Universidad de Tel Aviv, intitulado "Povos quase da mesma língua": não-/tradução, modernização, e as relações Brasil-Argentina, 1865-1900. En su trabajo, el autor nos presenta la Historia de la Traducción entre Brasil y la América Hispana durante el siglo XIX a partir del concepto de "Historia cruzada", considerado diferente y más amplio que el de Historia Comparada. En este trabajo, Preuss basa su estudio en los principios teóricos derivados de los Estudios descriptivos de la traducción, de la Sociología de la literatura, de la Historia del libro y de la noción de Historia cruzada. Al trazar este panorama de la historia de la traducción en América Latina, el autor explica también hasta qué punto el estudio de la traducción y la historia de la traducción fueron ignorados a lo largo del tiempo en el espacio latinoamericano y justifica en parte este movimiento por la posición periférica de América Latina en la geopolítica mundial del saber. Preuss rastrea en su artículo los momentos clave de la historia de América Latina y sus interconexiones y relevancia para la construcción del espacio de traducción en el tiempo, así como personajes históricos poco conocidos pero muy importantes para desarrollar esta historia de la traducción.

El volumen se completa con la entrevista realizada al traductor Javier Gorrais, especialista de la obra de Georges Perec. Durante la charla, Gorrais se detiene a hablar de la escritura perecquiana y de su desafío a la hora de ser traducida al español, subrayando la importancia de la crítica y el análisis literario en profundidad para lograr una traducción sólida y documentada.

Belas Infiéis, v. 8, n. 2, 2019. 
Va nuestro agradecimiento tanto a autores como a evaluadores. Los primeros respondieron a la invitación de hacer conocer sus trabajos a través de esta edición de Belas Infiéis demostrando desde el comienzo un fuerte compromiso con los plazos, las evaluaciones y las pautas de edición. Los segundos, desde las Universidades de Buenos Aires, Córdoba, Comahue y La Plata, colaboraron estrechamente con la coordinación de este número y se abocaron a una lectura cuidada y criteriosa en cada artículo asignado. Agradezco especialmente a mi colega, la Prof. Dra. Germana Henriques Pereira, editora en jefe de la revista, por la invitación a coordinar este número que tan gentilmente me hiciera durante nuestro encuentro en el Primer Congreso de Traductología realizado en París en abril de 2017. Va también nuestro especial reconocimiento a la labor de la editora asistente Patrícia Rodrigues Costa, quien supo ayudar y responder mis numerosas consultas durante todas las etapas de preparación de este número. No me queda más que desearles una placentera lectura de estos trabajos que contribuyen a la visibilidad de la disciplina traductológica en la tarea investigativa de las universidades argentinas.

Prof. Dra. Ana María Gentile (Universidad Nacional de La Plata, Argentina) Coordinadora $\mathrm{n}^{\circ}$ 2/2019 Abril de 2019 